\title{
Gerenciamento dos resíduos de serviços de saúde: uma questão de biossegurança
}

\author{
Health services waste management: \\ a biosafety issue
}

Leila Posenato Garcia 1

Betina Giehl Zanetti-Ramos 2

\footnotetext{
1 Programa de Pós-

Graduação em Saúde

Pública, Universidade

Federal de Santa Catarina,

Florianópolis, Brasil.

2 Curso de Pós-Graduação

em Química, Universidade

Federal de Santa Catarina,

Florianópolis, Brasil.

Correspondência

Leila Posenato Garcia

Rua Presidente Coutinho

316/1101, Florianópolis, SC

88015-230, Brasil.

leilapg@matrix.com.br
}

\begin{abstract}
The subject of "health services waste" is controversial and widely discussed. Biosafety, the principles of which include safeguarding occupational health, community health, and environmental safety, is directly involved in the issue of medical waste management. There are controversies as to the risks posed by medical waste, as evidenced by diverging opinions among authors: some advocate severe approaches on the basis that medical waste is hazardous, while others contend that the potential for infection from medical waste is nonexistent. The Brazilian National Health Surveillance Agency (ANVISA) has published resolution RDC 33/2003 to standardize medical waste management nationwide. There is an evident need to implement biosafety procedures in this area, including heath care workers' training and provision of information to the general population.
\end{abstract}

Medical Waste; Occupational Health; Public Health

\section{Introdução}

Apesar da Biossegurança no Brasil estar formatada legalmente para tratar da minimização dos riscos em relação aos organismos geneticamente modificados (pela Lei 8.974/1995 1), sua abrangência é muito mais ampla, pois envolve os organismos não geneticamente modificados e suas relações com a promoção de saúde no ambiente de trabalho, no meio ambiente e na comunidade.

Teixeira \& Valle 2 conceituam biossegurança como "o conjunto de ações voltadas para a prevenção, minimização ou eliminação de riscos inerentes às atividades de pesquisa, produção, ensino, desenvolvimento tecnológico e prestação de serviços, visando a saúde do homem, dos animais, a preservação do meio ambiente $e$ a qualidade dos resultados".

Devido às condições precárias do gerenciamento dos resíduos no Brasil, decorrem vários problemas que afetam a saúde da população como a contaminação da água, do solo, da atmosfera e a proliferação de vetores - e a saúde dos trabalhadores que têm contato com esses resíduos. Os problemas são agravados quando se constata o descaso com o gerenciamento dos resíduos de serviços de saúde, que serão o alvo da discussão deste artigo. 


\section{Problemática dos resíduos de serviços de saúde}

Os resíduos de serviços de saúde são geralmente considerados apenas aqueles provenientes de hospitais, clínicas médicas e outros grandes geradores. Tanto que os resíduos de serviços de saúde são muitas vezes chamados de "lixo hospitalar”. Entretanto, resíduos de natureza semelhante são produzidos por geradores bastante variados, incluindo farmácias, clínicas odontológicas e veterinárias, assistência domiciliar, necrotérios, instituições de cuidado para idosos, hemocentros, laboratórios clínicos e de pesquisa, instituições de ensino na área da saúde, entre outros.

Os grandes geradores possuem maior consciência a respeito do planejamento adequado e necessário para o gerenciamento dos resíduos de serviços de saúde. Contudo, os pequenos geradores muitas vezes não possuem essa consciência e os conhecimentos necessários. Muitas vezes também lhes falta infra-estrutura para realizar adequadamente o gerenciamento dos resíduos de serviços de saúde.

Além disso, parte dos resíduos domiciliares possui características que fazem com que se assemelhem aos resíduos de serviços de saúde. Por exemplo, pacientes diabéticos - que administram insulina injetável diariamente - e usuários de drogas injetáveis, geram resíduos perfurocortantes, que geralmente são dispostos juntamente com os resíduos domiciliares comuns.

No Brasil, devido às condições precárias do sistema de gerenciamento de resíduos, não há estatísticas precisas a respeito do número de geradores, nem da quantidade de resíduos de serviços de saúde gerada diariamente.

De acordo com dados da Pesquisa Nacional de Saneamento Básico, realizada pela Fundação Instituto Brasileiro de Geografia e Estatística (IBGE) ${ }^{3}$, são coletadas diariamente 228.413 toneladas de resíduos no Brasil. Em geral, estima-se que $1 \%$ desses corresponda aos resíduos de serviços de saúde, totalizando aproximadamente 2.300 toneladas diárias.

Ainda segundo dados do IBGE $3,74 \%$ dos municípios brasileiros depositam "lixo hospitalar" a céu aberto, 57\% separam os dejetos nos hospitais e apenas $14 \%$ das prefeituras tratam adequadamente os resíduos de serviços de saúde.

\section{Resíduos de serviços de saúde: composição, classificação e legislação}

Os resíduos de serviços de saúde são de natureza heterogênea. Portanto, é necessária uma classificação para a segregação desses resíduos. Diferentes classificações foram propostas por várias entidades, incluindo o Conselho Nacional do Meio Ambiente (CONAMA), a Agência Nacional de Vigilância Sanitária (ANVISA), governos estaduais e municipais.

Em 1993, o CONAMA publicou a Resolução no 5 4, que classifica os resíduos de serviços de saúde em quatro grupos: A, B, C e D. Enquadram-se no grupo A os que apresentam risco potencial à saúde pública e ao meio ambiente devido à presença de agentes biológicos, dentre eles, materiais que tenham entrado em contato com secreções e líquidos orgânicos, e materiais perfurantes ou cortantes. No grupo B, encontram-se os resíduos químicos; no grupo $\mathrm{C}$, os rejeitos radioativos; e no grupo D, os resíduos comuns.

A Resolução no 283 do CONAMA 5, de 2001, que atualiza e complementa a Resolução no 5, determina que caberá ao responsável legal pelo estabelecimento gerador a responsabilidade pelo gerenciamento de seus resíduos desde a geração até a disposição final.

Está em tramitação no Congresso Nacional, o Substitutivo ao Projeto de Lei no 203/1991, versando sobre a Política Nacional de Resíduos Sólidos. Segundo essa proposição, os resíduos de serviços de saúde seriam considerados resíduos especiais, exigindo um plano de gerenciamento e conferindo a responsabilidade ao gerador. Além disso, essa política estabelece punições no caso de serem cometidas infrações envolvendo resíduos sólidos perigosos.

Vários estados e municípios possuem legislações próprias específicas sobre o gerenciamento dos resíduos de serviços de saúde, estabelecendo normas para a classificação, segregação, armazenamento, coleta, transporte e disposição final desses resíduos. Contudo, as legislações em vigor não são claras e muitas vezes são conflitantes, o que provoca dúvidas e impossibilita a adoção de normas práticas eficazes para o gerenciamento dos resíduos de serviços de saúde em todo o país.

A ANVISA publicou em 4 de julho de 2000 a Consulta Pública no 48 , visando discutir o regulamento técnico sobre diretrizes gerais de procedimentos de manejo de resíduos de serviços de saúde, desde a geração até a disposi- 
ção final. O prazo para discussão era de quarenta dias, contudo, o assunto gerou bastante polêmica, houve muitas contribuições e críticas, e o texto original foi bastante modificado. Finalmente, em 5 de março de 2003, foi publicado no Diário Oficial da União o texto final da $R e$ solução RDC no 33, de 25 de fevereiro de 20037.

A resolução foi adotada pela ANVISA “considerando os princípios da biossegurança de empregar medidas técnicas, administrativas $e$ normativas para prevenir acidentes ao ser humano e ao meio ambiente". A classificação dos resíduos de serviços de saúde proposta pela resolução da ANVISA complementa a acima citada classificação do CONAMA. De acordo com a Resolução RDC no 33/2003 7, os resíduos de serviços de saúde são classificados em cinco grupos: Grupo A - potencialmente infectantes; Grupo B - químicos; Grupo C - rejeitos radioativos; Grupo D - resíduos comuns; e Grupo E perfurocortantes.

O responsável pelo estabelecimento gerador deverá implementar um Plano de Gerenciamento de Resíduos de Serviços de Saúde (PGRSS), definido como um conjunto de procedimentos de gestão, planejados e implementados baseando-se em normas científicas, normativas e legais, com o objetivo de minimizar a produção e proporcionar aos resíduos gerados um encaminhamento seguro, de forma eficiente, visando a proteção dos funcionários, a preservação da saúde pública, dos recursos naturais e do meio ambiente.

O PGRSS deve ser elaborado com base nas características e volume dos resíduos de serviços de saúde gerados, estabelecendo as diretrizes de manejo desses resíduos, incluindo as medidas de: segregação, acondicionamento, identificação, transporte interno, armazenamento intermediário, armazenamento temporário, tratamento, armazenamento externo, coleta e transporte externo e destinação final. Cada uma dessas etapas é indicada de maneira específica para cada tipo de resíduos de serviços de saúde.

Espera-se que, com a publicação da nova norma da ANVISA, sejam sanadas várias dúvidas a respeito do gerenciamento dos resíduos de serviços de saúde e que haja uma uniformização das medidas de gerenciamento desses resíduos em todo o território nacional, visando proteger a saúde dos trabalhadores envolvidos no manuseio dos resíduos, da comunidade em geral e do meio ambiente.

Os estabelecimentos geradores de resíduos de serviços de saúde têm um prazo de um ano para se adaptarem às normas. A partir desse momento, os estabelecimentos que não segui- rem as normas poderão ser punidos, recebendo desde notificações, até multas, de acordo com a Lei no 6.437/1977 8. A fiscalização caberá às vigilâncias sanitárias estaduais e municipais.

\section{Controvérsia sobre os riscos dos resíduos de serviços de saúde}

Risco pode ser entendido como a probabilidade de ocorrência de um resultado desfavorável, de um dano ou de um fenômeno indesejado (Organização Mundial da Saúde, 1988, apud Barbosa 9). Podem ser vários os danos decorrentes do mau gerenciamento dos resíduos de serviços de saúde, dentre eles destaca-se a contaminação do meio ambiente, a ocorrência de acidentes de trabalho - envolvendo profissionais da saúde, da limpeza pública e catadores - e a propagação de doenças para a população em geral, por contato direto ou indireto através de vetores 10 .

Alguns autores consideram exagerada a preocupação com os resíduos de serviços de saúde. Zanon 11 e Rutala \& Mayhall, 12 argumentam que os resíduos de serviços de saúde não constituem risco infeccioso para a comunidade e o meio ambiente, já que não há evidências científicas comprovando a existência de nexo causal entre o contato com o resíduo e a aquisição de doenças. Segundo esses autores, para a indução de uma doença infecciosa, são necessários vários fatores, que incluem: presença de um patógeno, dose de inoculação, virulência do patógeno, suscetibilidade do hospedeiro, e o fator mais comumente ausente, uma porta de entrada no hospedeiro. Portanto, de acordo com esses autores, para um resíduo apresentar risco infeccioso, ele deve conter patógenos com virulência e quantidade suficientes de modo que a exposição de um hospedeiro suscetível aos resíduos possa resultar em uma doença infecciosa.

Ainda de acordo com Rutala \& Mayhall 12, nos Estados Unidos não há evidência de que um trabalhador, do setor público ou privado, envolvido com os processos de coleta, transporte e disposição final dos resíduos tenha adquirido uma infecção a partir dos resíduos de serviços de saúde. Os únicos tipos de resíduos de serviços de saúde associados com a transmissão de doenças infecciosas são os perfurocortantes contaminados.

Em média, os resíduos domiciliares contêm mais microrganismos com potencial patogênico para humanos do que os de serviços de saúde 12. Os resíduos domiciliares que podem contribuir para o grande número de microrganismos incluem lenços descartáveis, fezes de ani- 
mais domésticos, fraldas descartáveis, absorventes higiênicos e alimentos perecíveis.

De acordo com Zanon 11, as publicações sobre a suposição de evitar um risco inexistente beneficiam a "indústria do lixo", favorecendo os que lucram financeiramente com a exploração da visão de periculosidade infecciosa dos resíduos de serviços de saúde, uma indústria considerada pelo autor um "campo minado" por envolver vultosos interesses financeiros. $\mathrm{O}$ autor considera ainda que a legislação que exige o tratamento diferenciado para os resíduos de serviços de saúde sobrecarrega os hospitais com despesas desnecessárias.

Por outro lado, há autores que são favoráveis ao tratamento diferenciado dos resíduos de serviços de saúde por considerarem que esses resíduos apresentam risco para a saúde do trabalhador, para a saúde pública e para o meio ambiente. Dentre esses autores, P. R. Rebello (comunicação pessoal) salienta a obrigação do Estado em determinar por meio de legislações específicas, a tomada de medidas para o correto gerenciamento dos resíduos de serviços de saúde, uma vez que ele possui papel de agente normatizador, protetor e promotor da saúde pública. Além disso, o autor enfatiza que as afirmações sobre a ausência de riscos dos resíduos de serviços de saúde podem induzir empresários da saúde a enxugar despesas com o gerenciamento dos resíduos, reforçando que é lícito querer enxugar custos, porém, não às custas de vidas (P. R. Rebello, comunicação pessoal). Esse é um tema relevante na atual conjuntura em que estão sendo realizadas pressões para a redução dos custos dos serviços de saúde.

Segundo Ferreira \& Anjos 13, afirmações a respeito da ausência de riscos dos resíduos de serviços de saúde não podem servir de justificativa para que as instituições de saúde não estabeleçam procedimentos gerenciais que reduzam os riscos associados a tais resíduos.

Tendo em vista a precariedade do tratamento e disposição final dos resíduos de serviços de saúde em nosso país - em que apenas pequena parte é depositada em aterros sanitários controlados - não se pode desprezar a contaminação ambiental provocada por esses resíduos. Silva et al. 14 salientam que diferentes microrganismos patogênicos presentes nos resíduos de serviços de saúde apresentam capacidade de persistência ambiental, entre eles Mycobacterium tuberculosis, Staphylococcus aureus, Escherichia coli, vírus da hepatite A e da hepatite B. O tempo de sobrevivência de alguns microrganismos nos resíduos sólidos está indicado na Tabela 1.

E. coli, Pseudomonas aeruginosa e S. aureus são microrganismos de grande interesse por
Tabela 1

Tempo de sobrevivência de alguns organismos em resíduos sólidos.

\begin{tabular}{ll}
\hline Organismos & Tempo de sobrevivência \\
\hline Bactérias & \\
Mycobacterium tuberculosis & $150-180$ dias \\
Salmonella sp. & $29-70$ dias \\
Leptospira interrogans & $15-43$ dias \\
Coliformes fecais & 35 dias \\
& \\
Vírus & \\
Vírus da hepatite B (HBV) & Algumas semanas \\
Pólio vírus - pólio tipo I & $20-170$ dias \\
Enterovírus & $20-70$ dias \\
Vírus da imunodeficiência humana (HIV) & $3-7$ dias \\
\hline
\end{tabular}

Modificada de: Organização Mundial da Saúde, 1993, apud Bidone 10.

estarem geralmente envolvidos na infecção hospitalar. Bidone 10 ressalta que esses microrganismos são os mais freqüentemente encontrados em análises microbiológicas dos resíduos de serviços de saúde.

É importante salientar ainda que diferentemente dos resíduos domiciliares comuns, os de serviços de saúde podem apresentar grande quantidade de substâncias químicas - como desinfetantes, antibióticos e outros medicamentos - decorrendo daí também o risco químico além do biológico 10. Além disso, a disposição conjunta dos resíduos contendo microrganismos e substâncias químicas pode provocar um aumento das populações bacterianas resistentes a certos antibióticos, detectadas no esgoto de hospitais 15. Dessa forma, o mau gerenciamento dos resíduos de serviços de saúde pode favorecer a propagação da resistência bacteriana múltipla a antimicrobianos.

Luna 16 afirma que fatores demográficos, como a destinação inadequada dos resíduos sólidos, estão envolvidos na determinação da emergência e reemergência de doenças infecciosas. Sendo assim, o tratamento adequado dos resíduos de serviços de saúde, especialmente aqueles contendo material biológico de pacientes acometidos por doenças novas ou emergentes - como a Síndrome Respiratória Aguda Grave (SRAG) - de patogênese ainda pouco conhecida, é de fundamental importância para a contenção da propagação dessas doenças.

Silva et al. 14 verificaram que há possibilidade de agravos à saúde humana e ambiental associados a diferentes microrganismos patogênicos, ressaltando o risco à exposição biológica quando prevalece o gerenciamento inade- 
quado dos resíduos de serviços de saúde, dentro e fora dos serviços de saúde.

\section{Discussão}

A questão dos resíduos de serviços de saúde não pode ser analisada apenas no aspecto da transmissão de doenças infecciosas. Também está envolvida a questão da saúde do trabalhador e a preservação do meio ambiente, sendo essas questões preocupações da biossegurança.

Segundo Rutala \& Mayhall 12, dentre o volume total de resíduos de serviços de saúde gerados nos hospitais norte-americanos, acredita-se que em torno de $10-15 \%$ sejam realmente perigosos e considerados “infectantes”. Esses resíduos incluem os perfurocortantes e os recipientes contendo culturas de microrganismos vivos. O restante são resíduos comuns e inclusive uma parte pode ser reciclada desde que haja uma segregação adequada.

Vários estudos demonstram que grande parte dos acidentes de trabalho com perfurocortantes ocorre no momento da disposição desses resíduos. Pournaras et al. 17 observaram durante seis anos 284 exposições a materiais biológicos em um hospital na Grécia. Os autores reportaram que as agulhas foram o item mais freqüentemente associado com injúrias, e os procedimentos de reencape e coleta dos resíduos foram causas comuns de injúrias. Shiao et al. 18 estudaram a ocorrência de acidentes com perfurocortantes no pessoal de apoio de um hospital tailandês, incluindo trabalhadores da lavanderia, limpeza, recepção e almoxarifado. Os autores constataram que $61 \%$ desses funcionários tinham sofrido uma injúria perfurocortante no último ano, mas apenas $25,4 \%$ reportaram sua injúria. A maioria dos acidentes ocorreu em funcionários da limpeza que manipulavam materiais perfurocortantes dispostos inadequadamente pela equipe clínica. A disposição inadequada estava associada com $54,7 \%$ de todas as injúrias.

No Brasil, a inexistência de um sistema de vigilância de acidentes de trabalho com material biológico faz com que haja poucos estudos epidemiológicos sobre injúrias ocupacionais envolvendo resíduos de serviços de saúde. Rapparini 19 investigou a incidência de acidentes de trabalho com exposição a material biológico no Município do Rio de Janeiro. Uma parte considerável dos acidentes reportados ocorreu durante o manuseio dos resíduos e devido à colocação de materiais perfurocortantes em locais impróprios, contabilizando $14,3 \%$ e $16,7 \%$ dos acidentes, respectivamente.
Marino et al. 20 relataram que, em seis anos, foram tratados aproximadamente 1.300 casos de acidentes envolvendo materiais biológicos no Hospital São Paulo. Desses acidentes, 90\% foram injúrias percutâneas, a maioria envolvendo agulhas. Os autores salientaram que tais casos são freqüentemente provocados pela disposição inadequada e reencape das agulhas. Contudo, sabe-se que em nosso país a subnotificação dos acidentes de trabalho é uma realidade que infelizmente impossibilita a detecção dos riscos potenciais a que os trabalhadores dos serviços de saúde estão expostos.

Acredita-se que o gerenciamento adequado dos resíduos possa contribuir significativamente para a redução da ocorrência de acidentes de trabalho, especialmente aqueles provocados por perfurocortantes. Dessa forma, também poderia ser reduzida a exposição percutânea dos trabalhadores dos serviços de saúde a materiais biológicos, uma medida no contexto da biossegurança que teria grande valor para a saúde ocupacional.

A Resolução RDC no 33/2003 da ANVISA 7 determina que programas de capacitação junto ao setor de recursos humanos devem fazer parte do PGRSS. O pessoal envolvido no gerenciamento dos resíduos deve ser capacitado na ocasião de sua admissão e mantido sob treinamento periódico.

Além dos trabalhadores dos serviços de saúde, também os das firmas terceirizadas de limpeza e os trabalhadores das companhias municipais de limpeza manuseiam os resíduos de serviços de saúde e estão expostos aos riscos inerentes quando esses resíduos são mal gerenciados. De acordo com Ferreira \& Anjos 13, a adoção do modelo de terceirização e privatização dos serviços de limpeza urbana pode ter um reflexo negativo na saúde dos trabalhadores, devido à elevada rotatividade que inviabiliza programas de treinamento e prevenção, resultando em um aumento do número de acidentes e na deterioração dos padrões já baixos de saúde desses trabalhadores.

Johnson et al. 21 e Braden et al. 22 verificaram a transmissão ocupacional de $M$. tuberculosis em decorrência da exposição a aerossóis infectantes no ambiente de trabalho. Os resultados de investigações epidemiológicas e laboratoriais sugeriram fortemente que a tuberculose multiresistente foi transmitida a cinco indivíduos que trabalhavam no tratamento de resíduos de serviços de saúde, nos Estados Unidos.

A disposição dos resíduos de serviços de saúde, juntamente com os resíduos comuns, também traz graves conseqüências para os excluídos sociais. Não há estatísticas precisas, 
contudo, o Fundo das Nações Unidas Para a Infância (UNICEF) 23, como parte da campanha Criança no Lixo Nunca Mais, enviou questionários a todas as prefeituras do Brasil, com o intuito de levantar dados sobre a realidade das crianças e adultos que vivem dos resíduos. Estima-se que haja mais de 200 mil catadores no Brasil e mais de 45 mil crianças que trabalham nos resíduos. Dados do UNICEF 23 indicam que em $68 \%$ dos municípios brasileiros há catadores nas ruas, em $66 \%$ há catadores nos aterros e em $36 \%$ também há crianças catando "lixo" nos aterros.

Segundo Ferreira \& Anjos 13, os catadores, ao remexerem os resíduos vazados à procura de materiais que possam ser comercializados ou servir de alimentos, estão expostos a todos os tipos de contaminação presentes nos resíduos. Os catadores, além de porem em risco sua própria saúde, servem de vetores para a propagação de doenças contraídas no contato com esses resíduos.

Vários episódios de mau gerenciamento dos resíduos de serviços de saúde com conseqüências desastrosas para a saúde dos excluídos sociais já foram destaque na mídia. Um incidente com grande repercussão foi o ocorrido em abril de 1994, no Lixão de Aguazinha, em Olinda. Mãe e filho haviam se alimentado com uma mama amputada encontrada entre os resíduos. O consumo de carne humana foi confirmado pela Vigilância Sanitária local 24. Tudo indica que incidentes envolvendo catadores e resíduos de serviços de saúde ocorram diariamente em vários locais do país, entretanto, não há dados estatísticos precisos.

\section{Propostas}

Três princípios devem orientar o gerenciamento dos resíduos: reduzir, segregar e reciclar. Esses princípios devem ser incorporados ao PGRSS de todos os estabelecimentos geradores.

A primeira providência para um melhor gerenciamento dos resíduos de serviços de saúde é a redução no momento da geração. Evitar o desperdício é uma medida que tem um benefício duplo: economiza recursos não só em relação ao uso de materiais, mas também no tratamento diferenciado desses resíduos.

Ferreira 25 salienta que a classificação dos resíduos é uma atividade complexa e, em muitos casos, ainda indefinida mesmo nos países desenvolvidos. Quanto mais perigoso é considerado o resíduo, maiores os cuidados necessários, e como conseqüência, maiores os custos envolvidos.
A segregação é o ponto fundamental de toda a discussão sobre a periculosidade ou não dos resíduos de serviços de saúde. Apenas uma parcela é potencialmente infectante, contudo, se ela não for segregada, todos os resíduos que a ela estiverem misturados também deverão ser tratados como potencialmente infectantes, exigindo procedimentos especiais para acondicionamento, coleta, transporte e disposição final, elevando assim os custos do tratamento desses resíduos.

Não existe teste que permita identificar objetivamente os resíduos infectantes 12 , portanto não é possível indicar o "índice de contaminação" ou "potencial infeccioso" de cada tipo de resíduo. Cada unidade geradora deveria ter um plano de gerenciamento, determinando o procedimento indicado para cada tipo específico de resíduo gerado.

Em muitos locais o que se observa é um comportamento de "tudo ou nada". Ou todos os resíduos são segregados como perigosos, ou nada é separado, e os resíduos de serviços de saúde acabam sendo dispostos como resíduos comuns ou domiciliares.

$\mathrm{O}$ treinamento dos funcionários para a correta segregação dos resíduos é bastante compensador, pois resulta no encaminhamento para coleta, tratamento e disposição final especial apenas dos resíduos que realmente necessitam desses procedimentos, reduzindo as despesas com o tratamento ao mínimo necessário.

Depois da segregação adequada, os resíduos de cada categoria deverão ser acondicionados corretamente, identificados e encaminhados para coleta, transporte e destinação final específicos. Os resíduos com características especiais nunca devem ser misturados com os resíduos comuns ou domiciliares.

Desde que feita uma segregação adequada, parte dos resíduos de serviços de saúde (por exemplo: embalagens, material de escritório) poderá ser reciclada, trazendo de volta ao ciclo produtivo materiais que seriam descartados, utilizando-os na produção de novos objetos. $\mathrm{O}$ processo de reciclagem traz benefícios para a comunidade, pois gera empregos e renda, além de contribuir para a redução da poluição ambiental, pois menos resíduos são depositados em aterros, e ainda implica o menor gasto de recursos naturais.

A pouca preocupação dos geradores dos resíduos de serviços de saúde com o gerenciamento desses resíduos reflete a atitude das autoridades governamentais, que em nosso país têm uma história de descaso com a saúde. A população por sua vez também exerce pouca pressão sobre as autoridades, contentando-se com a coleta apenas, não acompanhando o ge- 
renciamento dos resíduos até a disposição final e não exigindo um melhor tratamento desses resíduos. Isso fica evidente pela inexistência de um hábito de segregação dos resíduos nos domicílios brasileiros e à pequena porcentagem de municípios que oferecem coleta seletiva. Dados da Pesquisa Nacional do Saneamento Básico ${ }^{3}$ revelam que dos 5.507 municípios brasileiros, apenas 451 possuem coleta seletiva e 352 operam usina de reciclagem.

Perfurocortantes - como seringas e lâminas de barbear - podem ser encontrados tanto nos resíduos de serviços de saúde quanto nos domiciliares. A diferença entre os resíduos citados é a origem. Não se pode afirmar que esse tipo de resíduo seja mais "contaminado" ou "infectante" nos resíduos de serviços de saúde do que nos domiciliares, nem o contrário. Ambos os tipos de resíduos apresentam microrganismos patogênicos viáveis.

Tanto os resíduos de serviços de saúde quanto os domiciliares comuns representam risco para quem os manipula e entra em contato direto com eles (catadores, funcionários da limpeza do estabelecimento de saúde, funcionários dos serviços de recolhimento e disposição final dos resíduos) e para a comunidade, que é indiretamente exposta por meio dos aerossóis e vetores.

Portanto, em vez de deixar de lado os procedimentos diferenciados de acondicionamento, desinfecção, esterilização e destinação final dos resíduos de serviços de saúde, deveria ser realizada uma conscientização da população. Ao menos os resíduos domiciliares perfurocortantes deveriam ser segregados e acondicionados de maneira adequada em recipientes rígidos e estanques.

Todos os profissionais da saúde têm uma obrigação ética com a promoção de saúde. Se um trabalhador que recolhe o lixo sofre um acidente com uma seringa colocada juntamente com os resíduos domiciliares por uma pessoa

\section{Resumo}

O tema "resíduos de serviços de saúde" é polêmico e amplamente discutido. A biossegurança, por ter como princípios visar a manutenção da saúde do trabalhador e da comunidade, e a preservação do meio ambiente, está envolvida na questão do gerenciamento dos resíduos de serviços de saúde. Existem controvérsias quanto à periculosidade dos resíduos de serviços de saúde e aos riscos por eles representados, evidenciadas pelas opiniões divergentes entre autores: alguns defendendo medidas severas por considerarem esses resíduos perigosos e outros que, por não observarem nexo causal entre o contato com esses resíduos e a leiga é um problema, mas se essa seringa encontrada juntamente com os resíduos domiciliares for proveniente de um serviço de saúde, esse problema é muito mais grave.

Rebello 26 ressalta que o gerador de resíduos de serviços de saúde ao cumprir as normas de biossegurança estará prevenindo acidentes ao ser humano e ao meio ambiente, sendo este o seu papel e é isso que toda a sociedade espera dele.

\section{Conclusão}

A citada "ausência de risco" por "falta de evidência científica que comprove que os resíduos de serviços de saúde provocam doenças" não deve servir de justificativa para a negligência no gerenciamento desses resíduos. Não devemos nos influenciar por artigos estrangeiros que refletem uma realidade muito diferente da nossa, em que a maior parte dos resíduos de serviços de saúde é incinerada no local da geração, os aterros são controlados, não há catadores e os trabalhadores que lidam com os resíduos são mais protegidos. Nossa realidade é outra, os profissionais da saúde devem não só segregar seus resíduos e garantir que tenham uma disposição final adequada, mas também orientar a população para dispor corretamente os resíduos perigosos produzidos fora dos ambientes dos serviços de saúde, no intuito de promover a saúde de toda a comunidade.

Um caminho para solucionar a questão dos resíduos de serviços de saúde é o exercício do bom-senso, aliado com a educação e o treinamento dos profissionais de saúde, e o esclarecimento da população. A tomada de medidas no contexto da biossegurança, aliando economia de recursos, preservação do meio ambiente, ética e responsabilidade poderá garantir mais qualidade de vida no presente e um futuro mais saudável para as próximas gerações.

aquisição de doenças, não os consideram perigosos. Frente a isso, a Agência Nacional de Vigilância Sanitária publicou a Resolução RDC no 33/2003, pretendendo uniformizar o gerenciamento dos resíduos de serviços de saúde em nível nacional. Nesse contexto, evidencia-se a necessidade da tomada de medidas no âmbito da biossegurança, incluindo a educação $e$ o treinamento dos profissionais de saúde e o esclarecimento da população.

Resíduos de Serviços de Saúde; Saúde Ocupacional; Saúde Pública 


\section{Colaboradores}

A revisão da literatura e a discussão com análise crítica foi realizada em conjunto por ambas as autoras. $\mathrm{L}$. P. Garcia realizou a revisão do artigo, conferindo as referências bibliográficas. A revisão solicitada pelo editor de Cadernos de Saúde Pública foi realizada em conjunto por ambas as autoras, que aprovaram a versão final do manuscrito.

\section{Referências}

1. Brasil. Lei no 8974, de 5 de janeiro de 1995. Regulamenta os incisos II e V do parágrafo 1o do art. 225 da Constituição Federal, estabelece normas para o uso das técnicas de engenharia genética e liberação no meio ambiente de Organismos Geneticamente Modificados, autoriza o Poder Executivo a criar, no âmbito da Presidência da República, a Comissão Técnica Nacional de Biossegurança, e dá outras providências. Diário Oficial da União 1995; 06 jan.

2. Teixeira P, Valle S. Biossegurança: uma abordagem multidisciplinar. Rio de Janeiro: Editora Fiocruz; 1996.

3. Fundação Instituto Brasileiro de Geografia e Estatística. Pesquisa nacional de saneamento básico: limpeza urbana e coleta de lixo. http://www. ibge.gov.br/home/estatistica/populacao/condicao devida/pnsb/lixo_coletado/defaultlixo.shtm (acessado em 18/Set/2002).

4. Conselho Nacional do Meio Ambiente. Resolução 05, de 5 de agosto de 1993. Dispõe sobre o plano de gerenciamento, tratamento e destinação final de resíduos sólidos de serviços de saúde, portos, aeroportos, terminais rodoviários e ferroviários. Diário Oficial da União 1993; 31 ago.

5. Conselho Nacional do Meio Ambiente. Resolução 283, de 12 de julho de 2001. Dispõe sobre o tratamento e a destinação final dos resíduos dos serviços de saúde. Diário Oficial da União 2001; 1 out.

6. Agência Nacional de Vigilância Sanitária. Consulta pública no 48 , de 04 de julho de 2000 . Regulamento técnico sobre diretrizes gerais para procedimentos de manejo de resíduos de serviços de saúde. Diário Oficial da União 2000; 05 jul.

7. Agência Nacional de Vigilância Sanitária. Resolução RDC 33, de 25 de fevereiro de 2003. Dispõe sobre o Regulamento Técnico para o gerenciamento de resíduos de serviços de saúde. Diário Oficial da União 2003; 5 mar.
8. Brasil. Lei no 6.437, de 20 de agosto de 1977. Configura infrações à legislação sanitária federal, estabelece as sanções respectivas, e dá outras providências. Diário Oficial da União 1977; 24 ago.

9. Barbosa LMM. Glossário de epidemiologia e saúde. In: Rouquayrol MZ, Almeida Filho N, organizadores. Epidemiologia e saúde. $5 \underline{a}$ Ed. Rio de Janeiro: Medsi; 1999. p. 523-59.

10. Bidone FRA. Resíduos sólidos provenientes de coletas especiais: eliminação e valorização. Rio de Janeiro: Associação Brasileira de Engenharia Sanitária e Ambiental; 2001.

11. Zanon U. Riscos infecciosos imputados ao lixo hospitalar: realidade epidemiológica ou ficção sanitária? Rev Soc Bras Med Trop 1990; 23:163-70.

12. Rutala WA, Mayhall CG. Medical waste: SHEA position paper. Infect Control Hosp Epidemiol 1992; 13:38-48.

13. Ferreira JA, Anjos LA. Aspectos de saúde coletiva e ocupacional associados à gestão dos resíduos sólidos municipais. Cad Saúde Pública 2001; 17: 689-96.

14. Silva ACN, Bernardes RS, Moraes LRS, Reis JDP. Critérios adotados para seleção de indicadores de contaminação ambiental relacionados aos resíduos dos serviços de saúde: uma proposta de avaliação. Cad Saúde Pública 2002; 18:1401-9.

15. Kümmerer K. Significance of antibiotics in the environment. J Antimicrob Chemother 2003; 52:5-7.

16. Luna EJA. A emergência das doenças emergentes e as doenças infecciosas emergentes e reemergentes no Brasil. Rev Bras Epidemiol 2002; 5:229-43.

17. Pournaras S, Tsakris A, Mandraveli K, Faitatzidou A, Douboyas J, Tourkantonis A. Reported needlestick injuries among health care workers in a Greek general hospital. Occup Med 1999; 49:423-6.

18. Shiao JS, McLaws ML, Huang KY, Guo YL. Sharps injuries among hospital support personnel. J Hosp Infect 2001; 49:262-7. 
19. Rapparini C. Implementação de um programa de vigilância e instituição de quimioprofilaxia pósexposição ocupacional ao HIV no Município do Rio de Janeiro [Dissertação de Mestrado]. Rio de Janeiro: Faculdade de Medicina, Universidade Federal do Rio de Janeiro; 1999.

20. Marino CGG, El-Far F, Barsanti-Wey S, Medeiros EAS. Cut and puncture accidents involving health care workers exposed to biological materials. Braz J Infect Dis 2001; 5:235-42.

21. Johnson KR, Braden CR, Cairns KL, Field KW, Colombel AC, Yang Z, et al. Transmission of $M y$ cobacterium tuberculosis from medical waste. JAMA 2000; 284:1683-8.

22. Braden CR, Morlock GP, Woodley CL, Johnson KR, Colombel AC, Cave MD, et al. Simultaneous infection with multiple strains of Mycobacterium tuberculosis. Clin Infect Dis 2001; 33:42-7.
23. Fundo das Nações Unidas para a Infância. Fórum nacional lixo e cidadania: criança no lixo nunca mais. http://www.unicef.org/brazil/lixoecidadania/ acampanha/Index.htm (acessado em 20/Set/2002).

24. Ávila C, Moura AL. Saúde pública: os perigos do lixo hospitalar. Correio Braziliense 2001; $26 \mathrm{dez}$ http: / / www2.correioweb.com.br/cw/2001-1226/mat_26121.htm (acessado em 18/Set/2002).

25. Ferreira JA. Resíduos sólidos e lixo hospitalar: uma discussão ética. Cad Saúde Pública 1995; 11:314-20.

26. Rebello PR. Resíduos sólidos em serviços de saúde. In: Valle S, Telles JL, organizadores. Bioética e biorrisco: abordagem transdisciplinar. Rio de Janeiro: Editora Interciência; 2003. p. 391-412.

Recebido em 11/Abr/2003

Versão final reapresentada em 16/Out/2003 Aprovado em 28/Out/2003 